\title{
Sustainability: A New Paradigm of Corporate Reporting
}

\author{
Sergey A. Kuzubov, \\ Associate Professor, Faculty of Economic Sciences / School of Finance, \\ National Research University Higher School of Economics
}

In 2017, the School of Finance of HSE was selected by the American Council for International Research and Exchanges Board (IREX) as a partner for the Corporate Sustainability Leadership Education Program. The program aims to improve educational programs related to sustainable corporate development as well as provide online classes in the field of corporate sustainability that will be available for students and professionals.

Corporate sustainability can be seen as a new and evolving corporate governance paradigm. Within this paradigm, it is believed that although corporate growth and profitability are still important, it is necessary, however, that the company pursue goals aimed at sustainable development, which involves environmental protection, social justice and equality, and economic development.

We interviewed training manager Enrique Torres, who has over 20 years of international experience developing and implementing training and learning programs for private, governmental and non-governmental organizations in a variety of cultural contexts such as the Americas, Australia, Europe, and sub-Saharan Africa.

\section{Interview with Enrique Torres}

\section{Where were you born? Where did you study?}

I was born in the south of Spain and my parents immigrated to Australia when I was eight years old. I completed a Bachelor of Economics majoring in Accounting at Monash University and then a Master's in Business Education at Melbourne University.

\section{How and when did your interest in sustainability reports begin?}

In 2008 I was working for Médecins sans Frontières (an international medical humanitarian organization) and I was looking for a new career opportunity. I applied for a new position with the Global Reporting Initiative (GRI) to establish and manage their Learning Services, such as training, publications and also workshops and support programs that showed organizations how they could, in a concrete and simple way, apply the GRI Guidelines to complete their sustainability reporting. This allowed me to learn very quickly and in-depth, the major concepts of sustainability reporting. This meant I could develop practical support material for organizations to apply the very detailed and technical GRI Guidelines.

I left GRI three years ago in 2014 to establish a social enterprise focused on training and coaching in a variety of subject areas. One of the key areas I offer training is in sustainability reporting using the GRI. I also have a project with the International Integrated Reporting Council (IIRC) to establish and manage their $<$ IR $>$ Training Program. I also offer other services which are far from sustainability reporting, such as coordinating the management training workshops for Médecins sans Frontières staff who are going to work in projects as managers. I also give training and presentation skill workshops.

\section{What are the main differences between the GRI Standards and the IIRC Framework? Can we say that one is better than the other?}

It depends on your objectives. If an organization just wants to do a sustainability report then for sure the GRI Standards (introduced in October 2016) are more appropriate to use. If an organization wants to understand the relationships and interactions between the financial and non-financial aspects of their operations that help them create value over time, then the $<\mathrm{IR}>$ Framework is an appropriate point of reference.

The GRI Standards provide a detailed set of non-financial disclosures that organizations can manage and communicate through their non-financial report. The $<$ IR $>$ Framework takes a different approach. It is a framework that organizations can use to communicate their story of how they create value over time by using and impacting their different capitals. These include for example financial, human, intellectual, social, and environment capital. That is one key difference. The other key difference is that the GRI Standards provide a comprehensive list of detailed disclosures including economic, environmental, and social KPIs (Key Performance Indicators). On the other hand, the $<\mathrm{IR}>$ Framework is a principle-based framework. Although disclosures are provided, there is not the detail of the GRI Standards. For example, indicators are not provided. 


\section{Are the GRI Standards and the $<\mid \mathrm{R}>$ Framework compatible?}

Very much so, the reality is that many organizations that are experienced financial and non-financial reporters complete integrated reports based on the $<\mathrm{IR}>$ Framework that at the same time address the requirements of GRI. A good example of this is in South Africa where it is a Johannesburg Stock listing requirement for publicly listed companies to issue integrated reports. A significant proportion of these South African companies that issue integrated reports also address the GRI requirements. I am often asked by my course participants if they do an integrated report based on $<\mathrm{IR}>$ does that mean they no longer need to use GRI. My response is that they will still need to include in their integrated report their performance based on indicators. The GRI Guidelines and now Standards provide for them a comprehensive list of non-financial indicators to use for this.

\section{How can an organization that is preparing a GRI report in accordance with $\mathbf{G 4}$ and how can one use the GRI Standards get information on what is important for their stakeholders to be included?}

Stakeholder engagement needs to be something that occurs throughout the reporting process. It begins right from the start when you are planning the reporting process. At this point, you should engage mainly with your internal stakeholders. For example, the management team needs to be convinced of the benefits to the organization of doing a non-financial report. The staff in general will need to understand why the organization has made the decision to do non-financial reporting and what implications it will have for them. This also provides an opportunity to get feedback from staff to help in developing a reporting action plan.

When the organization is ready to consider what information will be included in the report, it is fundamental to engage with a wide range of internal and external stakeholders (such as staff, customers, clients, supplies, community and civil society groups) to find out what topics they consider important. For example, you can imagine that a dialogue with environmental groups will be very important for a mining company given the inevitable environmental implications of their operations.

It is important to point out that just because a certain stakeholder group says "this is an important topic" does not mean that the organization must automatically include that topic. The organization will need to go through a filtering process and reconcile the different stakeholder opinions to decide on what are its most important sustainability topics, (that is, its material topics). This is not an easy exercise as often what one stakeholder group considers important is completely different from another's priorities.
When an organization is gathering data and monitoring its most material topics, there is also stakeholder engagement. To start, the organization has to establish systems to gather data, such as on emissions, injury time lost, etc... The staff, who are especially involved in collecting and/or analyzing such data will need to understand what implications this will have for their work.

Finally, there is also stakeholder engagement during the writing of the report. The organization will need to compile the data that is to be included as information in the report. Now, let us imagine a very large mining company in Russia that has multiple divisions in different Russian regions. There are serious challenges to ensure that the different divisions are collecting the data in the same format which will allow compilation and then ensuring that all divisions provide the needed data in a timely manner so it can be compiled for the report. Even when the report is completed, there is stakeholder engagement with the executive team for the final check and sign off. Finally, there is stakeholder engagement when the report is completed. The launch of the report should be when the organization distributes the report to its stakeholders and encourages feedback from them on the report content and also how the stakeholders experienced the reporting process. This information is very important for organizations to continual improve their reporting.

\section{Are you aware of studies on the impact of non-financial reporting on a company's market value?}

Firstly, the Dow Jones Sustainability Index is an important point of reference on this question. Generally speaking, there is a positive correlation between a company's share price and its index score. Having said that, it is important to keep in mind that there are a variety of factors that influence a company's share price. Secondly, there have been a number of studies that have been done on the value of non-financial reporting. For example, KPMG does an international study every two years on the trends in corporate responsibility reporting amongst the very large companies. The last study was issued at the end of 2015 where they analyzed the non-financial reports from the largest 100 companies (N100) for each of 45 countries, (i.e., 4,500 companies in total).

The study showed that around $75 \%$ of the very large companies do some form of non-financial reporting. The key benefits/value that companies see are:

1. Strengthens their relationships with their stakeholders

2. Strengthens the name and reputation of the company. This has a positive impact on the company's social license to operate.

3. Become innovators and leaders in their industry In conclusion, there have been a significant number of studies done that show the value that the process of non-financial reporting brings to organizations. 


\section{Do you agree that the release of GRI Standards and the $<\mathrm{IR}>$ Framework is an important signal for investors?}

Very large investor groups do recognize that the information in financial reports does not provide a full picture of the value of the company. There is recognition that the major part of a company's value lays in its intangibles, i.e., the non-financials. However, this does bring up key questions that large investor groups have flagged as concerns when it comes to the information in non-financial reporting. 1) How do you quantify the non-financial impacts, i.e., put a money value on them? 2) How do you get information from non-financial reports that is focused on the most material sustainability topics for the company, i.e., cut through the 'good news stories'? Although these remain key concerns to be addressed, the KPMG international study does show that there has been an improvement in the quality of the information in the non-financial reports over the last 10 years.

As for the $<\mathrm{IR}>$ Framework, it is important to point out that it has a focus of providing investors with information on how an organization creates value over time considering the interaction and relationships of its capitals (financial and non-financial). The $<$ IR $>$ Framework was only released at the end of 2013 so it is still early for organizations to complete integrated reports based on the Framework. However, the early reaction from large investor groups has been very positive.

\section{Do you agree that organizations that prepare non-financial reports are making progress on reporting on their environmental or human capital? What can you say about companies that do not report on their most important environmental and human capital?}

It is close to the things that I have already said. The great advantage of going through a process of non-financial reporting is that it highlights issues that before may not have come up. If, for example, you track the issue of lost days through injuries, you can begin to identify problem areas and start to address them.

\section{- But if we imagine that organizations have no interest in bringing these up as important issues for themselves? What happens then?}

For sure, an organization can decide if, for example, injury time is a material topic for them or not. There is no external regulation that will say "these are the material issues that you must track". What can then happen? Let us talk about a construction company that does not identify injury time and lost days and even fatalities as a material topic. The company's stakeholders will for sure start to ask questions on what the company is doing to manage and report on this issue given that clearly injury rates is an important topic for a construction company. So, in the end the credibility of the company will be questioned when it is not transparent. Even if the construction company decides not to include injury time as a material topic in their report, for sure internally they will recognize it as such. If they do not, it will surely become a problem for the company not just for reputational, ethical or responsibility reasons, but from an operational and financial point of view, because it has lost days and productivity. So, a process of reporting means that key issues will be highlighted which will lead to discussions and decisions and result in internal improvements.

\section{Do mostly large companies issue non-financial reports?}

You are correct. And here I again reference the KPMG international study on corporate responsibility reporting, which focuses on very large companies. If you consider the last study from 2015, around 75\% of the largest 100 companies from 45 countries issue some form of non-financial report. For these very large companies, the question is not why should we do it but more but how can we do it better. However, it must be recognized that non-financial reporting is not a common practice with other organizations that are not and the hundred largest in a country. More so, it is the reality that non-financial reporting is more the exception than the rule for small and medium sized companies (SMEs).

Having said that, SMEs do complete non-financial reports and also address the GRI requirements. When I was in GRI we had a project which supported family companies with 20 employees or fewer to complete their sustainability reporting process using the GRI Guidelines. The interesting point is that many of the SMEs that we supported still continue to do non-financial reporting. They do it in a simple way that works for them and they continue to do it because it provides internal and external benefits for them. Related to this point, one important driver for SMEs to complete non-financial reports is pressure from large companies that are clients. Often these SMEs are suppliers to large companies that need key information of how their sustainability impacts their supply chain.

There are also examples of non-profit organizations that do non-financial reporting. With these, institutional donor requirements to explain the social and environmental impacts of their operations is often a key driver.

\section{How much time and how many people are necessary to prepare a Sustainability Report, say for an SME?}

It very much depends on the organization's specific situation. If we talk about a large company, it is necessary to have a coordination team with representatives from the key departments and divisions. It is also highly recommended to have a member from the executive team that very involved in the process. In fact, a number of large companies will have a Sustainability/CSR Director, who is part of the Executive Team. So, for a large company, there 
will be a significant number of people involved in the reporting process at different levels of depth.

However, when it is a small or medium sized company you have to be realistic given its resources. According to my experience of working with SMEs, you will need to spend some resources like money and people power, but it is not like you need have to have one full time staff member dedicated to this. What is necessary is to be smart about what you want to achieve and keep it simple and short.

\section{There is a problem that workers and managers do not clearly understand the benefits of non-financial reports issued in Russia. They do not trust them. Can you suggest what they can do to better understand the reasons and the value of non-financial reporting?}

The starting point for every organization in Russia that is not convinced by the arguments is to go and find out why the Russian organizations that do it do so. There are some large Russian non-financial reporting companies, mostly in mining and energy, which have international partners. Pressure from their international partners is surely an important driver for these companies. However, that is only one driver, so the question to ask is, what other reasons do these companies have? There are also Russian organizations that do non-financial reporting but do not have international partners, so what are their drivers? Next, I would advise a Russian organization that is not convinced of the value of non-financial reporting to get information on what the drivers are for companies outside of Russia. Russia is one of the BRICS countries, so what is going on in Brazil, India, South Africa and China? What are the trends there? You can see it in the KPMG international study I mentioned earlier. In the other BRICS countries, the proportion of companies doing non-financial reports is over $75 \%$. What are their drivers? I am certain that some of these drivers will also be relevant for Russian organizations.

\section{Which sectors have the highest proportion of companies that do non-financial reports?}

The GRI reports database is a very good tool for answering this question. The leading sectors in terms of number of organizations doing non-financial reports are financial services, mining, energy (including oil and gas), construction, food processing, and telecommunications. It is interesting to do some trend analysis over the last 10 years. In 2006, it was dominated by two to three sectors, by 2010 it had gone up to five to six sectors and now it is probably more than ten. So, the breadth of sectors where reporting organizations come from has increased significantly.

\section{How are reports that will be prepared in accordance with the GRI standards (not guidelines) checked?}

The GRI Standards does not say anything new or different compared to the GRI G4 Guidelines on this point. An organization needs to disclose whether their report has been externally assured and by whom as a requirement to be in accordance with GRI. However, there are no stated criteria that an external assurer should meet. Nor are there any requirements about which disclosures should be externally assured. The question of external assurance is a very debatable one. I expect that as organizations begin to use the GRI Standards for their non-financial reporting, there will be increasing pressure on GRI to take a stronger position on this question than in the past. It is one thing for GRI to say that they offered a guideline for organizations that wished to do a sustainability report. It is something different when you put forward standards for non-financial reporting.

Having said all of this, external assurance of non-financial reports has increased over the last 10 years. This is especially the case amongst the very large companies, for example, around two-thirds of the largest 250 companies have their non-financial reports externally assured.

\section{What developments in non-financial reporting do you expect over the coming, say, 10 years?}

I think in the next 10 years the number of organizations that do non-financial reporting as a matter of course will continue to increase. Additionally, I see the following developments having a direct impact on the quantity and quality of non-financial reporting.

4. The increasing influence of regulations. For example, the EU directive on non-financial reporting will result in the first lot of non-financial reports, which are required from EU organizations with 500+ workers, to come out starting in 2018.

5. The quality of the information in the reports is already increasing and I expect this to continue. Related to this, I expect there to be a more stringent position on external assurance of non-financial reports.

6. I expect that an increasing proportion of large companies that have a long history of financial and non-financial reporting will take the next step toward integrated reporting. I believe that integrated reporting is the future of reporting. 